\title{
A Prospective Study on Associated Conditions of Vertical Deviation
}

\author{
Dr.Bapanapalli Sailaja \\ Assistant Professor Of Ophthalmology, Osmania General Hospital, Hyderabad,
}

\begin{abstract}
Background: Hypertropia is a condition of misalignment of the eyes where the visual axis of one eye is higher than the fellow fixating eye. Hypotropia is the similar condition focus being on the eye with the visual axis lower than the fellow fixating eye. Dissociated Vertical Deviation is a special type of hypertropia leading to slow upward drift of one or rarely both eyes usually when the patient is inattentive. Vertical Deviation may be congenital or acquired and misalignment is due to imbalance in extra ocular muscle function.

Materials and Methods: This is a prospective study conducted on 32 patients with clinical diagnosis of vertical deviation.

Results: 32 cases with clinical diagnosis of Vertical Deviation were enrolled in this study. Esodeviation is the common associated deviation.

Conclusion: Superior oblique palsy was the frequent cause of hypertropia. Majority of them were congenital in origin. Majority presented with upward deviation of Right eye.

Keywords: Superior oblique palsy / Congenital fourth cranial nerve palsy, Inferior oblique over action, Inferior Rectus muscle palsy, Double elevator palsy.
\end{abstract}

\section{Introduction}

The vertical rectus muscles and the oblique muscles control both the vertical position of the eyes as well as the torsional position (keeping the eyes straight when the head is tilted.

Hypertropia is a condition of misalignment of the eyes (strabismus), whereby the visual axis of one eye is higher than the fellow fixating eye. Hypotropia is the similar condition, focus being on the eye with the visual axis lower than the fellow fixating eye. Dissociated Vertical Deviation is a special type of hypertropia leading to slow upward drift of one or rarely both eyes, usually when the patient is inattentive.

Hypertropia may be either congenital or acquired, and misalignment is due to imbalance in extraocular muscle function. The superior rectus, inferior rectus, superior oblique, and inferior oblique muscles affect the vertical movement of the eyes. These muscles may be either paretic, restrictive (fibrosis) or overactive effect of the muscles. Congenital cases may have developmental abnormality due to abnormal muscle structure, usually muscle atrophy / hypertrophy or rarely, absence of the muscle and incorrect placement.

Specific \& common causes include: Superior Oblique Palsy / Congenital fourth nerve palsy, Inferior Oblique overaction, Brown's Syndrome, Duane's Retraction Syndrome, Double elevator palsy, Fibrosis of rectus muscle in Graves Disease (most commonly inferior rectus is involved), Surgical trauma to the vertical muscles (e.g. during scleral buckling surgery or cataract surgery causing iatrogenic trauma to the vertical muscles).

Refractive errors such as hyperopia and Anisometropia may be associated abnormalities found in patients with vertical strabismus. The vertical miscoordination between the two eyes may lead to Strabismic amblyopia, (due to deprivation / suppression of the deviating eye), cosmetic defect (most noticed by parents of a young child and in photographs), Face turn, depending on presence of binocular vision in a particular gaze, diplopia or double vision - more seen in adults (maturity / plasticity of neural pathways) and suppression mechanisms of the brain in sorting out the images from the two eyes, Cyclotorsional deviation of the eyes (rotation around the visual axis), particularly when the root cause is an oblique muscle paresis causing the hypertropia.

\section{Objectives}

Prospective study of the associated conditions of vertical deviations such as esodeviation, exodeviation, age, sex, acquired conditions, congenital causes

\section{Materials And Methods}

This is a prospective study conducted, 32 patients with clinical diagnosis of vertical deviations attended to the outpatients department of Squint and Paediatric department of Sarojini Devi Eye Hospital were enrolled in this study. The incidence of associated conditions were analyzed and divided into categories. 
1.1 Inclusion Criteria: Congenital and acquired vertical deviations.

1.2 Exclusion Criteria: Iatrogenic vertical deviations.

1.3 Methodology 1: It is a prospective study, a detailed study of the patients who were attended the orthoptic department was done regarding age, sex incidence, general and systemic examination was done. A complete orthoptic examination was performed. Routine laboratory investigations were done and investigations like X-Ray and CT Scan were done when indicated. Cases of clinical interest and diversity are presented as case reports. A detailed history was elucidated regarding mode of onset of squint, and history of any hereditary bearing was looked into. History of trauma, fever, diplopia, head posture and other relevant symptoms and signs were elucidated.

1.4 Methodology 2: Vision was recorded by snellen's chart and E-test for distance and near. Cover-uncover test was done to determine the type of deviation. Ocular movements were tested in all cardinal directions and nyrestrictions or over actions were noted.

\begin{tabular}{|l|l|l|l|l|l|}
\hline S.No & AGE & MALE & FEMALE & TOTAL & Percentage \\
\hline 1. & 6m-6yrs & 01 & 02 & 03 & $9 \%$ \\
\hline 2. & $7-14 y r s$ & 02 & 04 & 06 & $19 \%$ \\
\hline 3. & $>14 y r s$ & 12 & 11 & 23 & $72 \%$ \\
\hline
\end{tabular}

1.5 Methodology 3: Angle of deviation was determined by Hirschberg test, Prismbar cover test, Krimsky's test, Worth's four dot test was done to know the presence of binocularity, Diplopia charting and Lees screen test were done, A cycloplegic refraction and fundus examination were done, DT was done when indicated under tropical anesthesia with $4 \%$ xylocaine drops.

\section{Results And Discussion}

32 Cases with clinical diagnosis of vertical deviation were enrolled in this study.

Table No 1

Figure No 1

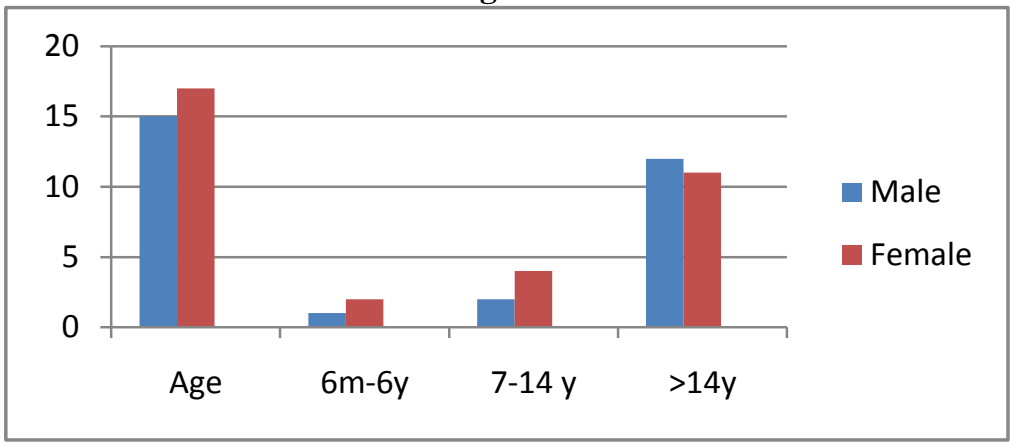

Table No 2 - Associated deviations

\begin{tabular}{|l|l|l|l|}
\hline S.No & Type of Deviation & No of cases & Percentage \\
\hline 1. & Esodeviation & 04 & $12 \%$ \\
\hline 2. & Exodeviation & 03 & $9 \%$ \\
\hline
\end{tabular}

Esodeviation is the common associated deviation. Figure No 2

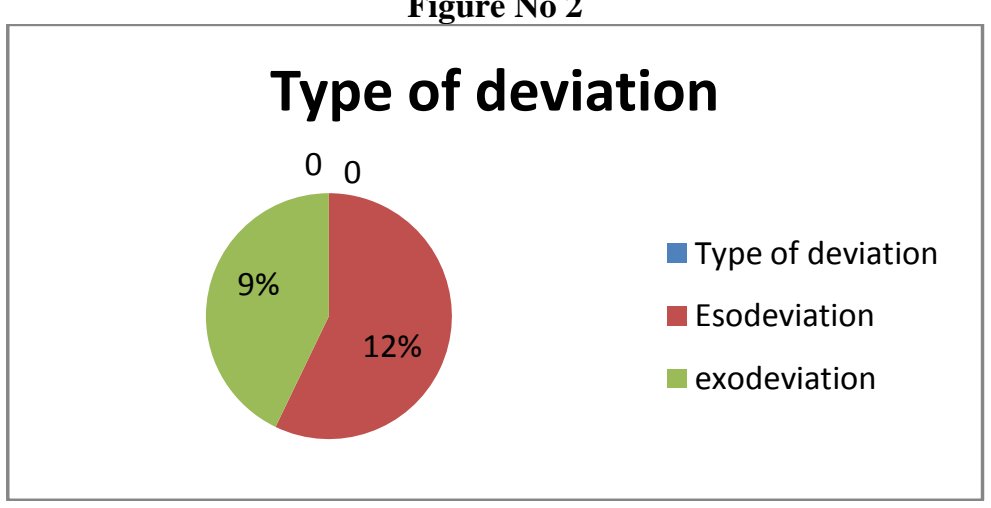


Table No 3 - Positive Family History

\begin{tabular}{|l|l|l|}
\hline $\begin{array}{l}\text { No of cases with positive family history of } \\
\text { squint }\end{array}$ & Total no of cases & Percentage \\
\hline 02 & 32 & $6 \%$ \\
\hline
\end{tabular}

Figure No 3

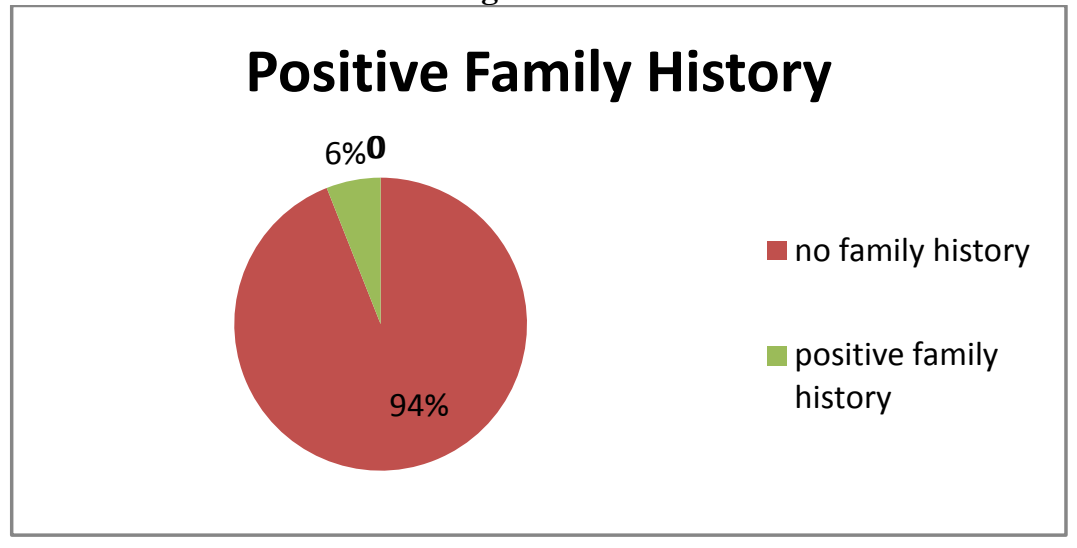

Table No 4- Laterality

\begin{tabular}{|l|l|l|}
\hline Laterality & No of cases & Percentage \\
\hline Right & 22 & $69 \%$ \\
\hline Left & 9 & $28 \%$ \\
\hline
\end{tabular}

Figure No 4

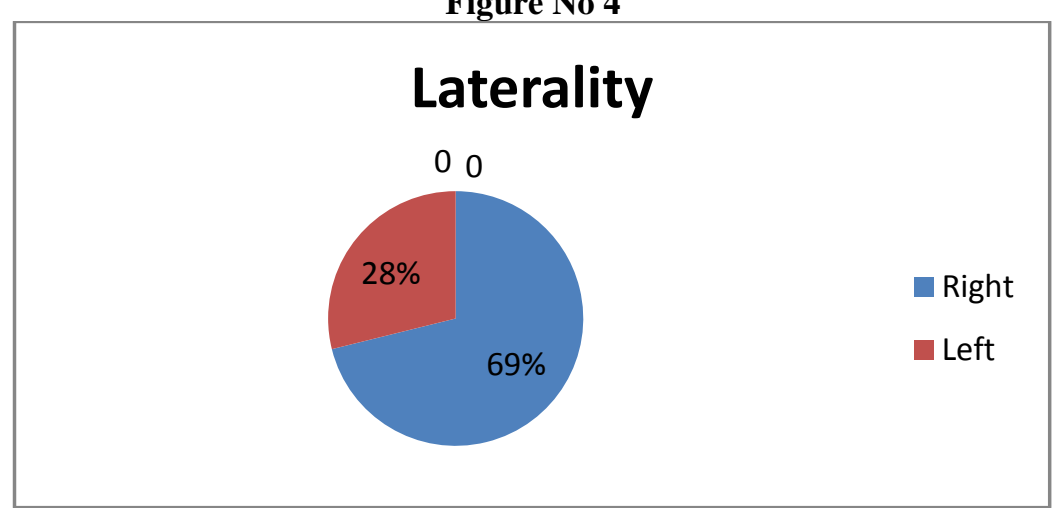

Table No 5 - Aetiology

\begin{tabular}{|l|l|l|}
\hline S.No & No of cases & Percentage \\
\hline Congenital & 19 & 59 \\
\hline Acquired & 13 & 41 \\
\hline
\end{tabular}

Figure No 5

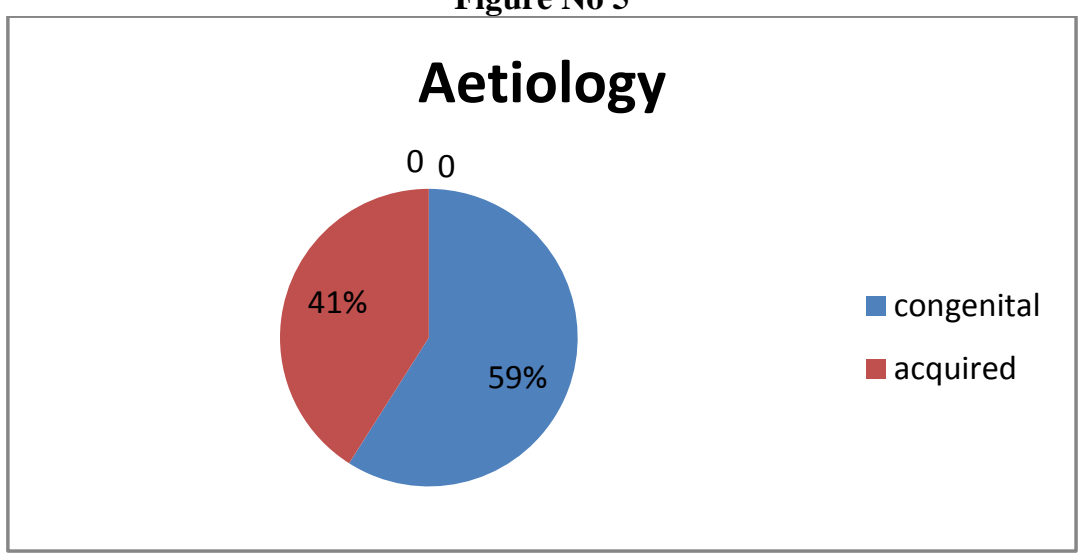


Table No 6- Types of vertical deviations

\begin{tabular}{|l|l|l|l|}
\hline S.No & RHT & LHT & DVD \\
\hline 1. & 22 & 08 & 02 \\
\hline percentage & $69 \%$ & $25 \%$ & $6 \%$ \\
\hline
\end{tabular}

Table No 7- Causes

\begin{tabular}{|c|c|c|c|c|c|c|c|c|c|c|c|}
\hline \multirow[t]{2}{*}{ S.No } & \multicolumn{4}{|c|}{$\begin{array}{l}\text { Due to } \\
\text { muscles }\end{array}$} & \multicolumn{4}{|c|}{ Single muscle paralysis } & \multirow[t]{2}{*}{$\begin{array}{l}\text { Double } \\
\text { elevator palsy }\end{array}$} & \multirow[t]{2}{*}{$\begin{array}{l}\text { Restriction } \\
\text { of muscle }\end{array}$} & \multirow{2}{*}{$\begin{array}{l}\text { Multiple } \\
\text { muscle palsies } \\
\text { (IIICN- } \\
\text { Palsy) }\end{array}$} \\
\hline & SR & IR & SO & IO & SR & IR & SO & IO & & & \\
\hline 1. & 00 & $\mathbf{0 0}$ & 00 & 06 & 01 & 06 & 08 & 01 & $\mathbf{0 2}$ & 01 & 05 \\
\hline$\%$ & & & & 19 & 3 & 19 & 25 & 3 & 6 & 3 & 16 \\
\hline
\end{tabular}

Table No 8- Causes and of under action over action

\begin{tabular}{|c|l|l|l|l|}
\hline Description & \multicolumn{2}{|c|}{ Under action } & \multicolumn{2}{c|}{ Over action } \\
\hline & Mechanical & Paralytic & Primary & Secondary \\
\hline No of cases & $\mathbf{0 1}$ & $\mathbf{2 3}$ & $\mathbf{0 6}$ & $\mathbf{0 0}$ \\
\hline Percentage & $\mathbf{0 3 \%}$ & $\mathbf{7 2 \%}$ & $\mathbf{1 9 \%}$ & \\
\hline
\end{tabular}

Table No 9- Refractive errors

\begin{tabular}{|l|l|l|l|l|}
\hline S.No & \multicolumn{4}{|c|}{ Refractive error } \\
\hline & Hyperopia & Myopia & Anisometropia & Ambloypia \\
\hline 1. & 02 & 02 & 01 & 03 \\
\hline$\%$ & 6 & 6 & 3 & 9 \\
\hline
\end{tabular}

Table No 10- Systemic causes

\begin{tabular}{|l|l|l|l|l|l|l|l|}
\hline S.No & $\begin{array}{l}\text { Hyper } \\
\text { tension }\end{array}$ & $\begin{array}{l}\text { Diabetis } \\
\text { mellitus }\end{array}$ & Trauma & $\begin{array}{l}\text { Hyper } \\
\text { telerosim }\end{array}$ & $\begin{array}{l}\text { Billateral } \\
\text { blepharo } \\
\text { phimosis }\end{array}$ & $\begin{array}{l}\text { Congenital progressive } \\
\text { external } \\
\text { ophthalmoplegia }\end{array}$ & $\begin{array}{l}\text { naso } \\
\text { phyringial } \\
\text { fibroma }\end{array}$ \\
\hline 1. & $\mathbf{0 3}$ & $\mathbf{0 4}$ & $\mathbf{0 6}$ & $\mathbf{0 1}$ & $\mathbf{0 1}$ & $\mathbf{0 1}$ & $\mathbf{0 1}$ \\
\hline$\%$ & $\mathbf{9}$ & $\mathbf{1 2}$ & $\mathbf{1 9}$ & $\mathbf{3}$ & $\mathbf{3}$ & $\mathbf{3}$ & $\mathbf{3}$ \\
\hline
\end{tabular}

\section{Conclusion}

Superior oblique palsy was the frequent cause of hypertropia. Majority of them were congenital in origin.Majority presented with upward deviation of Right eye. Esotropia was the frequent association. Trauma was also one of the important associated factors. Superior oblique was the frequently involved muscle followed by Inferior rectus in trauma. Majority of the patients were young adults. Incidence of vertical deviation is almost equal in males and females. Systemic causes are most frequent in old age.

\section{References}

[1]. David A.Plager.,Edward G.Buckley, Marshall M.Parks, Gunter K.Noorden “ Strabismus surgery basic and advance strategies” page 106-109.2004.

[2]. Duke.Elder S., "System of Ophthalmology". Volume VIStrabismus1949

[3]. E.Ugene M.Helveston “ The strabismus minute” Vol II, no 16., Copy right@ 2000.

[4]. EM Helveston Trans Am ophthalmol Soc.1980:78:734-779" Dissociated vertical deviation-a clinical and laboratory study."

[5]. E. Aurell and K. Norrsell,Department of Ophthalmology, County Hospital, Mölndal, Sweden, “

[6]. A longitudinal study of children with a family history of strabismus: factors determining the incidence of strabismus. $\mathrm{Br} \mathrm{J}$ Ophthalmol. 1990 October; 74(10): 589-594.

[7]. Godeiro K D., Pinto AG., Souza Filbo JP., Petrilli AM., Nakanami CR.” Traumatic tear of inferior rectus muscle treated with inferior oblique anterior transposition" Int Ophthalmol.2005;26(4-5).,185-189.

[8]. Gunter K. von Noorden, MD; Elizabeth Murray, CO; Susie Y. Wong, MD Arch Ophthalmol. 1986;104(12):1771-1776" Vertical strabismus in monofixation

Journal of American Association for Pediatric Ophthalmology and Strabismus, Volume 5, Issue 1, Page 5

[9]. Gunter K.Von Noorden,M.D.,"Binocular Vision and Ocular Motiltiy” 1990.

[10]. Main J.Trimble R. "Diagnosis and management of ocular motility disorders". $2^{\text {nd }}$ ed.oxford.Blackwell 1991.

[11]. Melek NB, Mendoza T, Ciancia AO" Bilateral recession of superior rectus muscles: its influence on A and V pattern strabismus."

[12]. Muhammad Abbas, Hafiz Ur Rahman, Imran Azam Butt,Nahid Gani "Prevalence and mode of presentation of vertical deviation in squint patients" Vol.30,No.2,July-December 2005 of RMJ.

[13]. Peyman-Sanders. Goldberg.,’Principles and Practice of Ophthalmology" 1987 Vol. III.

[14]. Scott WE, Drummond GT, Keech RV.Department of Ophthalmology, University of Iowa Hospitals, Iowa City 52242Aust N Z J Ophthalmol. 1989 Aug;17(3):281-8."Vertical offsets of horizontal recti muscles in the management of A and V pattern strabismus."

[15]. Tollefson MM, Mohney BG, Diehl NN, Burke JP " Incidence and types of childhood hypertropia" Ophthalmology. 2006 Jul; 113(7):1142-5. Epub 2006 Apr 27.

[16]. Varn MM, Saunders RA, Wilson ME" Combined bilateral superior rectus muscle recession and inferior oblique muscle weakening for dissociated vertical deviation.” N. Edgar Miles Center for Pediatric Ophthalmology, Department of Ophthalmology, Medical University of South Carolina, Charleston 29425-2236, USA 
[17]. Velez FG, Ela-Dalman N, Velez G.Department of Ophthalmology, Jules Stein Eye Institute, University of California, Los Angeles, California, USA" Surgical management of dissociated vertical deviation associated with A-pattern strabismus" J AAPOS. 2009 Feb;13(1):31-5. Epub 2008 Dec 13

[18]. Ziakas NG, Woodruff G, Smith LK, Thompson JR Department of Ophthalmology, University of Leicester, Leicester Royal Infirmary, UK. ziakas.” A study of heredity as a risk factor in strabismus” Eye (Lond). 2002 Sep;16(5):519-21. 